\title{
Assessing the Microbial Quality of Commercial Aquaculture Probiotics by Next Generation Sequencing Revealed Faecal Bacteria and Bacteria of Public Health Significance
}

\author{
Toms Joseph \\ Central Institute of Fisheries Technology \\ Bibindas K.S \\ Central Institute of Fisheries Technology \\ Lakshmi T.R \\ Central Institute of Fisheries Technology \\ Mahmoud Eltholth ( $\square$ m_eltholth@yahoo.com ) \\ University of Edinburgh \\ Francis Murray \\ University of Stirling
}

\section{Research Article}

Keywords: Next Generation Sequencing, Microbiome, Aquaculture Probiotics, Shrimp

Posted Date: July 28th, 2021

DOI: https://doi.org/10.21203/rs.3.rs-740362/v1

License: (c) (i) This work is licensed under a Creative Commons Attribution 4.0 International License.

Read Full License 


\section{Abstract}

There is an increasing trend in the application of probiotics in aquaculture as an environment friendly alternative to antibiotics for the control and treatment of diseases. The microbiome of commercial aquaculture probiotics were evaluated using NGS to understand the microbial species composition vis-àvis the label on the probiotic product. Bacteria belonging to 12 bacterial species stated on the labels of five probiotics were absent. The sequence reads of the microorganisms declared on the label ranged from $0.28-79 \%$ for the probiotics tested while the rest were contaminants. The number of contaminant bacteria varied from 2 to 15 for the tested products. All products were found to have at least one bacterial species that were potentially pathogenic or of fecal origin. To our knowledge this is the first study that utilized the potential of NGS to assess the microbial quality of commercial aquaculture probiotics providing novel insights in understanding the microbial composition of probiotic products which are otherwise difficult to identify. It is proposed that probiotic products shall be approved for use in aquaculture after determining the performance efficiency by in vivo trails in farms, analysis of bacterial composition and concentration which shall be displayed on product labels.

\section{Introduction}

During the last few decades, worldwide usage of commercial probiotics in shrimp aquaculture has shown tremendous growth ${ }^{1}$. Probiotic products with various benefits that include controlling diseases, promoting growth, enhancing feed digestion, and improving pond water quality have been introduced in aquaculture ${ }^{2,3}$. Easy availability of aquaculture probiotics in the market reflect the increasing usage of these products in the industry and the expansion of global marketplace for probiotic products. The market of aquaculture probiotics used for shrimp farming in India is estimated to be more than $\$ 100$ million. In a recent study, $100 \%$ of the $P$. vannamei farmers surveyed in the four districts of Andhra Pradesh, India used probiotics ${ }^{4}$.

Even though the aquaculture probiotics are highly commercialized and widely used, effective implementation of regulations to assess the quality of probiotics is still lacking in most countries. Microbial composition displayed on label of many commercial probiotics do not accurately match with their actual content ${ }^{5}$ and the recent trend in aquaculture probiotic industry of formulating products with complex blend of microbes call out for methods ideal for effective analysis of the relative numbers of mixed bacterial species. The probiotic may not contain all the bacterial species claimed on the product label or contain contaminant microorganisms with undesirable effects on both animal and aquaculture environment. The reliability of traditional microbiological methods for enumeration of multiple strains of probionts present in a single probiotic is doubtful, due to low selectivity and reciprocal inhibition in plate ${ }^{6}$. Even microbial enumeration with different culture media may not be able to detect all groups of microorganisms present in a probiotic product ${ }^{6}$. Molecular biology techniques like real-time quantitative PCR (RT-qPCR or qPCR $)^{8,9,10}$, fluorescent in-situ hybridization (FISH) ${ }^{11,12}$, flow cytometry ${ }^{13,14,15}$, MALDITOF mass spectrometry ${ }^{16}$ etc. were used to determine the microbial quality of commercial probiotics. 
Even though these techniques are able to detect and/or quantify the microbial species stated on the label, they have limited ability to detect microbes that are present as contaminants in the probiotic.

The variable and conserved regions of $16 \mathrm{~S}$ rDNA makes it an ideal indicator for taxonomic classification of bacteria. The 16S rDNA sequencing of cultures isolated from the probiotic can be employed for identifying the microbial content of probiotic products. However, this method is laborious, time consuming and requires isolation of cultures from different media. High throughput sequencing using shorter regions of $16 \mathrm{~S}$ rDNA produce more read depth and allow an effective analysis of complex bacterial species bypassing the need of culturing and limitations thereof. Next generation sequencing is being widely used for analyzing microbial diversity of great variety of environments, including soil ${ }^{17,18}$, sea ${ }^{19,20}$, air ${ }^{21}$ and other agriculture food samples ${ }^{22}$. In this study Illumina sequencing based NGS using single 16S phylogenetic marker was employed to identify the microorganisms present in commercial aquaculture probiotics. This method could successfully be used to ascertain the veracity of the bacterial species declared on the label and also to determine the contaminant microorganisms present in the product.

\section{Results}

\subsection{Taxonomic Classification of Quality Reads}

Based on the $16 \mathrm{~S}$ amplicon sequencing of the $\mathrm{V} 3$ region for product codes $1,2,3,4$ and 5 , quality reads of $251,967,63,460,34,724,31,134$ and 154,932 were obtained respectively from the corresponding $446,988,96,231,44,064,38,484$ and 194,555 raw sequences. The sequences were submitted in the NCBI BioSample database under accession numbers SAMN12598838, SAMN12598839, SAMN12598840, SAMN12598841 and SAMN12598842. The quality reads were clustered into 1,655, 1,684, 536, 649 and 310 OTUs respectively for product codes 1 to 5 . The 16S rRNA gene is present among the members of the paraphyletic prokaryotic domains, Bacteria and Archaea $^{23}$ and sequencing of hypervariable regions of the gene can be used for identification of bacteria in a complex sample. The aim of our work was to identify bacterial species present in the products, hence processed reads falling under the bacterial domain were only considered for further taxonomic classification. The graphical depiction of taxonomic distribution of processed reads from each product is given in Fig. 1. From each hierarchy rank, sequences categorized as unknown were eliminated before calculating percentage of reads. Quality reads were found to be low at the kingdom level itself for products 3 and 4 which may be either due to sequences that were not categorised to any bacteria or the sequences were unknown. Due to the high sequence similarity between cyanobacteria and chloroplast ${ }^{24}$, some sequences under the phylum cyanobacteria could not be further resolved to any bacterial class and were recorded as chloroplast and considered as unknown from thereon. The high number of chloroplast reads in product 2 and 4 contributed to the reduced number of total quality reads of these products from class level onwards. The claim made by probiotic manufacturers on the microbial species present in the product and the percentage of reads that each species contributes in each probiotic as revealed by next generation sequencing is given in Table 1. The sequence reads of microorganisms that were declared on the label ranged from $0.28-79 \%$ for the 
probiotics tested. All the microorganisms claimed by the manufacturers were present in products 1 and 4 contributing 60.77 and $0.28 \%$ of the sequence reads respectively while the rest were contaminant microorganisms.

\subsection{Qualitative Analysis of Metagenomic Sequences}

The metagenomic sequences of all the products revealed discrepancies against product declarations and revealed incongruity between the label claims and the actual bacterial content of products (Supplementary table, S1). Microorganisms with sequence abundance greater than $0.01 \%$ were included in our results. All products contained several contaminant microorganisms when evaluated at both genus and species level. The ratio of number of bacteria actually present to the total number of bacteria claimed on the label for products 1 to 5 were 2:2, 1:5, 2:4, 1:1 and 3:9 respectively. The number of contaminant bacteria ranged from 5 for product 3 to 30 for product 4 at the genus level (Supplemetary Table, S1A). The presence of Bacillus spp. was confirmed in all the screened probiotic products with Bacillus subtilis in four products, $B$. licheniformis in two products and B. coagulans and B. pumilus in one product each as expected. None of the products contained any species of Bacillus not specified in the labels, however products 2, 3 and 5 did not contain many of the Bacillus species mentioned in the labels. Pediococcus acidilactici was present in product 1 as per the label declaration, while in products 2 and 5 it was present as a contaminant. Two products that claimed to contain nitrifying bacteria; Nitrobacter and Nitrosomonas could not be detected even at the genus level. Propionibacterium acne was observed as the most occurring contaminant with incidence in three products. All tested products had at least one bacterial species which are either potentially pathogenic or of faecal origin; Acinetobacter baumannii, $A$. junii, Enterobacter cloacae, Enterococcus faecium, E. coli, P. acne and Pseudomonas aeruginosa.

It is evident that some organisms that were categorized till genus level were not grouped to its respective species (Supplemetary Tables, S1A and S1B). The entire quality reads sorted to a particular taxonomic rank may not be always resolved to its sub-categories in next level of hierarchy due to the inabilities of databases $^{25}$. In product 2, 3 and 5, the Bacillus genera were not classified to its species level for $13,12.1$ and $0.45 \%$ of the sequences, respectively.

\subsection{Relative Abundance of Bacterial Species in the Probiotic Products}

Relative percentage of abundant bacterial species (with $\geq 0.1 \%$ of total quality reads) present in the five products is graphically represented in Fig. 2. The proportion of bacterial species present as contaminants ranged between 14.82 to $91.1 \%$ for the products tested. Among the bacteria declared on the label, Bacillus species constituted major proportion of three products with a share of $84.76,83.02$ and $80.72 \%$ in products 1,3 and 5 , respectively whereas the corresponding value were $9.27 \%$ in product 2 and $8.90 \%$ in product 4 . Although we were able to confirm the presence of $P$. acidilactici in product 1, Bacillus subtilis in product 2 and 4, and Bacillus licheniformis and Bacillus pumilus in product 5 which were anticipated as per the labels, their relative abundance was negligible compared to the contaminants. In product 2 and 4 , the ratio of contaminant organisms was almost 10 times higher than the declared bacteria on label. 
The presence of fecal indicator organisms was observed in three products; $E$. cloacae (6.83\%) in product 3 , E. faecium (9.83\%) in product 4 and $E$. coli $(18.96 \%)$ in product 5 . Incidence of multiple numbers of potential human infectious bacteria ( $A$. baumannii, $A$. junii, $P$. acne and $P$. aeruginosa) with a total share of $22.39 \%$ in product 2 raises concern on health safety aspect of the probiotic. The presence of potential pathogenic microorganisms such as $P$. acne $(9.59 \%$ in product 1 and $4.04 \%$ in product 4$)$ and $P$. aeruginosa ( $0.88 \%$ in product 3 ) were also observed. The bacteria under genera Acidovorax, Staphylococcus and Streptococcus contributed 27.5 relative percentage in product 2. The relative abundance of contaminant bacteria; Streptococcus thermophiles (74.64\%) was higher than that of its only declared organism, Bacillus subtilis in product 4.

\section{Discussion}

In the present study, metagenomic sequencing was employed to evaluate claims regarding bacterial composition on the labels of five commercial aquaculture probiotics sold in India. A probiotic product is said to be reliable if bacterial strains are present in right composition and concentration as claimed on the label. Culture-based isolation and identification of probiotic bacterial strains may result in missing out of few bacterial species ${ }^{26}$. The traditional method of culture-based enumeration of specific organisms will only identify bacteria that are able to grow and reproduce on synthetic media under definite conditions $^{27}$. High Throughput DNA sequencing can offer resolution required for examining all microbial communities including the contaminant and unculturable organisms in mixed samples to the preferred taxonomy up to strain level ${ }^{28}$. In this study, the microbial quality of probiotic products were evaluated through NGS technique by means of the discriminative power of $\mathrm{V} 3$ region sequencing of 16S rDNA. Identification of bacteria were done only up-to species level as the disclosure on labels were up to that level. NGS sequencing of the V2 and V3 regions of 16SrRNA were found to be most suitable for distinguishing most bacterial species up to the genus level ${ }^{29}$. NGS has the potential to detect unexpected microbes ${ }^{30}$ with the advantage of being high-throughput having ability to generate large sequence data.

It was evident that all the probiotic products tested contained several contaminant bacteria and the microbial composition of the product were not in agreement with the label information of the product. Aquaculture probiotic products approved in Vietnam were found to contain bacterial strains not declared on the product labels. Also, many bacterial species including Bacillus spp. declared on the label were not isolated ${ }^{26}$. In our study, only 2 products ( 1 and 4 ) contained all bacterial species claimed by the manufacturer. The relative abundance of the sole declared organism, B. subtilis was just $8.9 \%$ in Product 4. Bacillus is one of the most widely used bacteria incorporated in majority of the aquaculture probiotics. When Bacillus spp., is used in aquaculture pond, it can easily become part of the culture environment by competing with pathogenic or non-pathogenic bacteria ${ }^{31}$. Bacillus spp. was reported to act as a growth promoter $^{32}$, inhibit pathogen ${ }^{33}$, improve nutrient digestibility ${ }^{34}$, enhance water quality ${ }^{35}$ and ameliorate reproduction ${ }^{36}$. Bacillus spores are able to survive under various conditions including desiccation, freezing, elevated temperatures, chemicals, increased pressure and even radiation ${ }^{37}$. The ability of Bacillus spp. to form spores will help in the long-term storage of probiotic products. 
In the present study, absence of $B$. licheniformis and $B$. coagulans in product $2, B$. subtilis and Lactobacillus acidophilus in product 3 , Alkaligenes faecalis, $B$. amyloliquefaciens, $B$. megaterium and $B$. polymyxa in product 5 and Nitrobacter sp., and Nitrosomonas sp. in products 2 and 5 highlighted the poor correlation between the label claims and actual content of the products. The nitrifying bacteria are beneficial as they increase the number of microbial species in water and improve the water quality by eliminating ammonia and nitrate toxicity ${ }^{38,39}$. The accumulation of ammonia nitrogen and nitrite are two major toxic factors that directly affect the economic benefits of aquaculture $40,41,42$.

One of the foremost concerns to be considered while evaluating the quality of commercial probiotics is the existence of unspecified organisms within the product. $P$. acne, an anaerobic bacterium causing acne and one of the most abundant organisms found on human skin $^{43}$, is a common taxonomic group found in three out of the five probiotic products analyzed. This organism was totally unexpected in the products and might have got incorporated into the product due to lack of good manufacturing practices and proper quality control during production process. Based on sequence analysis it was found that there were many microorganisms that were not declared in the labels but were found in the product. E. faecium was present in product 5 as a contaminant and this bacteria was found to decrease the mortality of European eel due to edwardsiellosis ${ }^{44}$. Even though Enterococci are Lactic Acid Bacteria, their application in animal and human health are hindered by occurrence of virulence and antibiotic resistant genes and pathogenicity ${ }^{45,46}$. Enterococcus spp. is neither recommended for the QPS status by the European Food Safety Authority (EFSA) ${ }^{47}$ nor have GRAS status ${ }^{48}$, in spite of recent scientific knowledge allowing differentiation of commensal from pathogenic strains ${ }^{49,50}$. Due to limited therapeutic options, vancomycin-resistant Enterococcus faecium (VREF) is of great clinical significance. The clinical $E$. faecium isolates in Germany exhibiting resistance to vancomycin was $26.1 \%$ in $2017^{51}$. Arthospira platensis was present in product 3 , a filamentous cyanobacterium widely used as a prebiotic in aquaculture because of its best-known nutritional qualities ${ }^{52}$. Interestingly in Product 4 , an organism that was not claimed on the label, Streptococcus thermophiles, was found to be present. S. thermophiles is a moderate thermophile and a widely used human probiotic ${ }^{53}$. The presence of E. faecium, A. platensis and $S$. thermophilus in the products cannot be considered as unintentional. It is suggested that the product label should specify all the organisms that are incorporated in a product and their intended use. Several strains of $S$. thermophilus have also been shown to have several in vitro and in vivo probiotic properties ranging from the production of a range of short-chain fatty acids to moderately high survivability levels under simulated gastrointestinal tract conditions ${ }^{54,55,56}$.

The existence of human infectious bacteria; $A$. baumannii, $A$. junii and $P$. acne, human and fish pathogen; Pseudomonas aeruginosa and faecal contaminants; E. coli, E. cloacae and E. faecium in probiotic was unanticipated. The use of probiotics with contaminant bacteria carrying potential risks and of unknown provenance in aquaculture farms could cause a major shift in natural microbial community ${ }^{57}$. There is a high risk due to human exposure to the pathogenic contaminant bacteria present in aquaculture probiotics, during handling of such probiotics or probiotic fed aquatic animals and by dissemination to surrounding environment and terrestrial animals. 
To our knowledge, this is the first study that has employed NGS for quality analysis of commercial aquaculture probiotics. Inconsistencies in the bacterial composition against the label declarations and occurrence of Bacillus as the integral constituent of products observed in the current study were also observed in similar reports on the culture dependent evaluation of aquaculture probiotics ${ }^{5,26}$. The microbiological analysis of seven probiotics commonly used in Vietnamese shrimp culture, revealed that all the bacteria as stated on the label could not be detected while few bacteria that were not declared; Aerococcus sp., Klebsiella spp., and Bacillus spp. were present in the products ${ }^{26}$.

Since knowledge about the heterogeneity and growth requirements of contaminant bacteria in a probiotic are limited, isolation and identification of these bacteria will be difficult with traditional microbiological techniques or even with molecular methods. High-throughput based metagenomics studies can identify entire range of organisms that were not declared on the label. However, some closely related species would have little divergence among the variable regions of $16 \mathrm{~S}$ rDNA. Therefore, discrimination of such species that belongs to the same group as Bacillus subtilis group will be difficult and the categorization will be terminated at the genus level ${ }^{25}$. Since $16 \mathrm{~S}$ database is incomplete, bacterial species present in the tested products which were unclassified and recorded as unknown could not be identified. However, this weakness of the technique has not affected the results since the major focus of our work was to isolate contaminant microorganisms.

It is mandatory that all aquaculture probiotics sold in the Indian market have to be registered with Coastal Aquaculture Authority (CAA). The approval is solely based on the absence of antibiotics in the product. Many probiotics sold in the Indian market donot carry information on the bacterial composition and concentration of each species, the method or the frequency of application. The claims on the effectiveness of the products is often highly exaggerated. Aquaculture farmers purchase the probiotic products based on the claims of the merchandise, and hence misleading, incorrect, or deceptive labeling on products need to be avoided. The findings from the current study raises concerns regarding the quality of aquaculture probiotics in the interest of the stakeholders including the farmers and the final consumer.

It is evident that all the probiotics screened in this study do not fulfill the basic requirement of labeling the exact content of the probiotic product. Besides, the occurrence of potential pathogenic organisms in the product is an added public health concern. This underlines the need for stringent quality control and regular screening by competent authorities to monitor the manufacture of aquaculture probiotics and implementing a legislation system for such an emerging and growing industry. The effect due to application of probiotic product shall clearly be mentioned on the label and the information provided on the label shall be evaluated based on on-farm trials before the product is approved for use.

\section{Materials And Methods}

\subsection{Commercial Aquaculture Probiotics}

Five brands of aquaculture probiotics marketed in India that revealed count and content of the bacterial species on the label procured from retail aquaculture shops in Andhra Pradesh, India were selected for the 
study. The products were assigned codes in the sequential order from 1 to 5 . The labels on products 1,3 and 4 provided bacterial composition up to species level while products 2 and 5 revealed species information for all bacteria other than for two bacteria belonging to genera; Nitrobacter and Nitrosomonas. All products were in powder form and were within the expiry period at the time of analysis. After procurement, based on the instructions on the label, the products were stored appropriately in cool, dry place and away from light till sampling was done. All probiotics were sampled on the day of opening of the packets.

\subsection{DNA extraction and PCR amplification}

Total DNA was extracted from 250 mg of probiotic product using the HiPurA ${ }^{\text {TM }}$ Soil DNA Purification Kit (Himedia, India) following manufacturer's instructions. During sampling, thorough mixing and pooling of each product powder was performed aseptically. The V3 region of the 16S rRNA gene was amplified using the primers V3F (5'-CCAGACTCCTACGGGAGGCAG-3') and V3R (5'-CGTATTACCGCGGCTGCTG-3'). PCR amplification was carried out with 2X Master mix (Thermo Scientific, US) in a Veriti 96 well Thermal Cycler (Thermo Fisher Scientific, US) with the following PCR conditions; initial denaturation at $95{ }^{\circ} \mathrm{C}$ for 5 min, 35 cycles of $95^{\circ} \mathrm{C}$ for $45 \mathrm{~s}, 59^{\circ} \mathrm{C}$ for $45 \mathrm{~s}$ and $72{ }^{\circ} \mathrm{C}$ for $45 \mathrm{~s}$, followed by a final extension step at $72{ }^{\circ} \mathrm{C}$ for $5 \mathrm{~min}^{29}$.

\subsection{Library preparation and sequencing}

Library of V3 region was prepared using NEBNext ${ }^{\circledR}$ Ultra ${ }^{\mathrm{TM}}$ DNA Library Prep Kit for Illumina (NEB, USA). Manufacturer's instructions were followed for preparation of the amplicon for illumina MiSeq sequencing platform. Adapter ligated PCR amplicons were sequenced at AgriGenome Labs Pvt Ltd, India.

\subsection{Preprocessing, processing, and taxonomic classification of sequences}

The initial raw reads generated from sequencing were subjected to sequential stages of filtration. Spacer and conserved region were trimmed from the paired-end data and consensus V3 region sequence was constructed using ClustalO program ${ }^{58}$ (Sievers et al. 2011). Chimeras were removed using the de-novo chimera removal software UCHIME ${ }^{59}$ (Edgar et al. 2011) implemented in the USEARCH tool. The preprocessed reads obtained were pooled and clustered into Operational Taxonomic Units (OTUs) based on their sequence similarity using Uclust program ${ }^{60}$ (Edgar 2010) (similarity cutoff $\left.=0.97\right)$. QIIME ${ }^{61}$ (Caporaso et al. 2010) program was used for the entire downstream analysis. Representative sequences were identified for each OTU and aligned using PyNAST ${ }^{62}$ (Caporaso et al. 2009) with GreenGenes ${ }^{63}$ (DeSantis 2006) core set. The reads corresponding to the OTUs after singleton removal were taken as the final processed reads. Further these quality reads were aligned against reference chimeric data sets. The sequences that did not have any alignment with GreenGenes database were categorized as Unknown. Taxonomy classification to phylum, class, order, family, genus and species was performed using RDP classifier $^{64}$ (Wang et al. 2007) against SILVA OTUs database ${ }^{65}$ (Quast et al. 2012). 


\section{Declarations}

\section{Funding}

The study was part of an Indo-UK joint research project on "Evaluating Costs and Benefits of Prophylactic Health Products (PHPs) and Novel Alternatives on Smallholder Aquaculture Farmers in Asia and Africa (IMAQulate)" (BT/IN/Indo-UK/BBSRC-Aqua/36/TCJ/2015-16) under DBT-BBSRC-DFID, funded by Department of Biotechnology, India and carried out at ICAR-Central Institute of Fisheries Technology, Kerala, India.

\section{Conflicts of interest/Competing interests}

The authors declared no potential conflicts of interest with respect to the research, authorship, and/or publication of this article.

\section{Ethics approval}

Not applicable

\section{Consent to participate}

Not applicable

\section{Consent for publication}

The authors transfer to Springer the non-exclusive publication rights.

\section{Availability of data and material}

Not applicable

\section{Code availability}

Not applicable

\section{Contributions}

TCJ: Resources, conceptualization, methodology, experimental design, validation writing- original draft, supervision, project administration and funding acquisition. KSB: Investigation, writing-original draft, bioinformatic analysis. TRL: Bioinformatic analysis. MME and FM: Review of manuscript and editing

\section{Acknowledgement}

The study was a part of an Indo-UK joint research project on "Evaluating Costs and Benefits of Prophylactic Health Products (PHPs) and Novel Alternatives on Smallholder Aquaculture Farmers in Asia and Africa (IMAQulate)" (BT/IN/Indo-UK/BBSRC-Aqua/36/TCJ/2015-16) under DBT-BBSRC-DFID, funded 
by Department of Biotechnology, India and carried out at ICAR-Central Institute of Fisheries Technology, Kerala, India. The authors are thankful to Dr. Ravishankar C. N, Director, ICAR-CIFT for continuous support and guidance.

\section{Data availability}

The datasets generated during the current study are available from the corresponding author on reasonable request

\section{References}

1. Soccol, C.R. et al. The potential of probiotics: a review. Food Technol. Biotechnol.48, 413-434 (2010).

2. Irianto, A. \& Austin, B. Probiotics in aquaculture. J. Fish. Dis.25, 633-642 (2002).

3. Wang, Y.B., Li, J.R \& Lin, J. Probiotics in aquaculture: challenges and outlook. Aquaculture281,1-4 (2008).

4. Joseph, T. C. et al. Prophylactic health products use in Penaeus vannamei farming in Andhra Pradesh: Perception of shrimp farmers of north, central and south coastal regions. Indian J. Fish.68, 143-147 (2021).

5. Nimrat, S. \& Vuthiphandchai, V. In vitro evaluation of commercial probiotic products used for marine shrimp cultivation in Thailand. Afr. J. Biotechnol.10, 4643-4650 (2011).

6. Silvi, S., Rumney, C.J. \& Rowland, I.R. An assessment of three selective media for bifidobacteria in faeces. J. Appl. Bacteriol.81, 561-564 (1996)

7. Charteris, W.P., Kelly, P.M., Morelli, L. \& Collins, J.K. Selective detection, enumeration and identification of potentially probiotic Lactobacillus and Bifidobacterium species in mixed bacterial populations. Int. J. Food. Microbiol.35,1-27 (1997).

8. Sheu, S.J. et al. Use of tuf gene-based primers for the PCR detection of probiotic Bifidobacterium species and enumeration of Bifidobacteria in fermented milk by cultural and quantitative real-time PCR methods. J. Food Sci.75, M521-M527 (2010).

9. Herbel, S.R. Species specific quantification of probiotic lactobacilli in yoghurt by quantitative realtime PCR. J. Appl. Microbiol.115,1402-1410 (2013).

10. Sattler, V.A., Mohnl, M \& Klose, V. Development of a strain-specific real-time PCR assay for enumeration of a probiotic Lactobacillus reuteri in chicken feed and intestine. PloS One9, e90208 (2014).

11. Bernardeau, M., Vernoux, J.P. \& Gueguen, M. Usefulness of epifluorescence for quantitative analysis of lactobacilli in probiotic feed. J. Appl. Microbiol.91,1103-1109 (2001).

12. Lahtinen, S.J., Gueimonde, M., Ouwehand, A.C., Reinikainen, J.P. \& Salminen, S.J. Comparison of four methods to enumerate probiotic Bifidobacteria in a fermented food product. Food Microbiol. 23, 571577 (2006). 
13. Chen, S., Cao, Y., Ferguson, L.R., Shu, Q. \& Garg, S. Flow cytometric assessment of the protectants for enhanced in vitro survival of probiotic lactic acid bacteria through simulated human gastro-intestinal stresses. Appl. Microbiol. Biotechnol.95, 345-356 (2012).

14. Doherty, S.B et al. Use of viability staining in combination with flow cytometry for rapid viability assessment of Lactobacillus rhamnosus GG in complex protein matrices. J. Microbiol. Methods82, 301-310 (2010).

15. Martin-Dejardin, F. et al. A way to follow the viability of encapsulated Bifidobacterium bifidum subjected to a freeze-drying process in order to target the colon: Interest of flow cytometry. Eur. $J$ Pharm. Sci.49, 166-174 (2013).

16. Angelakis, E., Million, M., Henry, M. \& Raoult, D. Rapid and accurate bacterial identification in probiotics and yoghurts by MALDI-TOF mass spectrometry. J. Food Sci.76, M568-M572 (2011).

17. Roesch, L.F. et al. Pyrosequencing enumerates and contrasts soil microbial diversity. ISME J. 1, 283290 (2007).

18. Rawat, N. \& Joshi, G.K. Bacterial community structure analysis of a hot spring soil by next generation sequencing of ribosomal RNA. Genomics111, 1053-1058 (2019).

19. Huber, J. A. Microbial population structures in the deep marine biosphere. Science318, 97-100 (2007)

20. Pongsilp, N. \& Nimnoi, P. Inoculation of Ensifer fredii strain LP2/20 immobilized in agar results in growth promotion and alteration of bacterial community structure of Chinese kale planted soil. Sci. Rep.10,1-3 (2020).

21. Leung, M.H., Wilkins, D., Li, E.K., Kong, F.K. \& Lee, P.K. Indoor-air microbiome in an urban subway network: diversity and dynamics. Appl. Environ. Microbiol.80, 6760-6770 (2014).

22. Beans, C. Inner Workings: Companies seek food safety using a microbiome approach. Proc. Natl. Acad. Sci.114,13306-13308 (2017).

23. Ziesemer, K.A. et al. Intrinsic challenges in ancient microbiome reconstruction using 16S rRNA gene amplification. Sci. Rep.5,16498 (2015).

24. Raven, J.A. \& Allen, J.F. Genomics and chloroplast evolution: what did cyanobacteria do for plants? Genome Biol.4, 209 (2003).

25. Schmidt, V., Gomez-Chiarri, M., Roy, C., Smith, K. \& Amaral-Zettler, L. Subtle microbiome manipulation using probiotics reduces antibiotic-associated mortality in fish. MSystems2, e00133-17 (2017).

26. Uddin, G.M.N. et al. Identification and antimicrobial resistance of bacteria isolated from probiotic products used in shrimp culture. PLoS One10, e0132338 (2015).

27. Davis, C. (2014) Enumeration of probiotic strains: review of culture-dependent and alternative techniques to quantify viable bacteria. J. Microbiol. Methods 103, 9-17

28. Patro, J.N. et al. Culture-independent metagenomic surveillance of commercially available probiotics with high-throughput next-generation sequencing. mSphere1, e00057-16 (2016).

29. Chakravorty, S., Helb, D., Burday, M., Connell, N. \& Alland, D. A detailed analysis of 16 S ribosomal RNA gene segments for the diagnosis of pathogenic bacteria. J. Microbiol. Methods69, 330-339 (2007). 
30. Vayssier-Taussat, M. et al. Next generation sequencing uncovers unexpected bacterial pathogens in ticks in western Europe. PLoS One8, e81439 (2013).

31. Buruiana, C.T., Profir, A.G. \& Vizireanu, C. Effects of probiotic Bacillus species in aquaculture-an overview. The Annals of the University of Dunarea de Jos of Galati. Fascicle-VI. Food Technol.38, 917 (2014).

32. Rengpipat, S., Phianphak, W., Piyatiratitivorakul, S. \& Menasveta, P. (1998). Effects of a probiotic bacterium on black tiger shrimp Penaeus monodon survival and growth. Aquaculture, 167, 301-313.

33. Moriarty, D.J.W. Control of luminous Vibrio species in penaeid aquaculture ponds. Aquaculture164, 351-358 (1998).

34. Mujeeb Rahiman, K. M., Jesmi, Y., Thomas, A. P., \& Mohamed Hatha, A. A Probiotic effect of Bacillus NL110 and Vibrio NE17 on the survival, growth performance and immune response of Macrobrachium rosenbergii (de Man) Aquac. Res.4, e120-e134 (2010).

35. Shishehchian, F., Yusoff, F.M. \& Shariff, M. The effects of commercial bacterial products on macrobenthos community in shrimp culture ponds. Aquac. Int.9, 429-436 (2001).

36. Ghosh, S., Sinha, A. \& Sahu, C. Effect of probiotic on reproductive performance in female live bearing ornamental fish. Aquac. Res.38, 518-526 (2007).

37. Setlow, P. The germination of spores of Bacillus species: what we know and don't know. J. Bacteriol.196,1297-1305 (2014).

38. Mohapatra, S., Chakraborty, T., Kumar, V., DeBoeck, G. \& Mohanta, K.N. Aquaculture and stress management: a review of probiotic intervention. J. Anim. Physiol. Anim. Nutr.97, 405-430 (2013).

39. Zorriehzahra, M.J. et al. Probiotics as beneficial microbes in aquaculture: an update on their multiple modes of action: a review. Vet Q36, 228-241(2016).

40. Alcaraz, G., Chiappa-Carrara, X., Espinoza, V. \& Vanegas, C. Acute toxicity of ammonia and nitrite to white shrimp Penaeus setiferus postlarvae. J. World Aquac. Soc.30, 90-97 (1999).

41. Ebeling, J.M., Timmons, M.B. \& Bisogni, J.J. Engineering analysis of the stoichiometry of photoautotrophic, autotrophic, and heterotrophic removal of ammonia-nitrogen in aquaculture systems. Aquaculture257, 346-358 (2006).

42. Körner, S., Das, S.K., Veenstra, S. \& Vermaat, J.E. The effect of pH variation at the ammonium/ammonia equilibrium in wastewater and its toxicity to Lemna gibba. Aquat. Bot.71, 7178 (2001).

43. Salter, S.J. et al. Reagent and laboratory contamination can critically impact sequence-based microbiome analyses. BMC Biol.12, 87 (2014).

44. Chang, C.I. \& Liu, W.Y. An evaluation of two probiotic bacterial strains, Enterococcus faecium SF68 and Bacillus toyoi, for reducing edwardsiellosis in cultured European eel, Anguilla anguilla L. J. Fish Dis.25, 311-315 (2002).

45. Baccouri, O. et al. Probiotic potential and safety evaluation of Enterococcus faecalis OB14 and OB15, isolated from traditional tunisian testouri cheese and rigouta, using physiological and genomic 
analysis. Front. Microbiol.10, 881 (2019).

46. Hanchi, H., Mottawea, W., Sebei, K. \& Hammami, R. The genus Enterococcus: between probiotic potential and safety concerns-an update. Front. Microbiol. 9, 1791(2018).

47. EFSA Panel on Biological Hazards (BIOHAZ) Scientific Opinion on the maintenance of the list of QPS biological agents intentionally added to food and feed (2012 update) (2012). J. EFSAhttps://doi.org/10.2903/j.efsa.2012.3020 (Lastly accessed: 04 July 2021).

48. Ogier, J.C. \& Serror, P. Safety assessment of dairy microorganisms: the Enterococcus genus. Int. J. Food Microbiol.126, 291-301(2008).

49. Montealegre, M.C., Singh, K.V. \& Murray, B.E. Gastrointestinal tract colonization dynamics by different Enterococcus faecium clades. J. Infect. Dis.213,1914-1922 (2016).

50. Bonacina, J. et al. A genomic view of food-related and probiotic Enterococcus strains. DNA Res. 24,124 (2017).

51. Markwart. R. et al. The rise in vancomycin-resistant Enterococcus faecium in Germany: data from the German Antimicrobial Resistance Surveillance (ARS). Antimicrob. Resist. Infect. Contro/8,147(2019).

52. Gupta. S., Gupta, C., Garg, A.P \& Prakash, D. Prebiotic efficiency of blue green algae on probiotics microorganisms. J. Microbiol. Exp. 4:1-4 (2017).

53. Charalampopoulos, D. \& Rastall, R.A. Prebiotics and probiotics science and technology. (eds. Charalampopoulos, D. \& Rastall, R.A.) 612-613 (Springer, 2009)

54. Lecomte, X., Gagnaire, V., Lortal, S., Dary, A \& Genay. M. Streptococcus thermophilus, an emerging and promising tool for heterologous expression: advantages and future trends. Food Microbiol. 53, 29 (2016).

55. Ashraf, R. \& Smith, S.C. Commercial lactic acid bacteria and probiotic strains- tolerance to bile, pepsin and antibiotics. Int. Food Res. J.23, 777-789 (2016).

56. Iyer, R., Tomar, S.K., Kapila, S., Mani, J \& Singh. R. Probiotic properties of folate producing Streptococcus thermophilus strains. Food Res. Int.43,103-110 (2010).

57. Watts, J., Schreier, H., Lanska, L. \& Hale, M. The rising tide of antimicrobial resistance in aquaculture: sources, sinks and solutions. Mar. Drugs15, 158 (2017).

58. Sievers, F. et al. Fast, scalable generation of high-quality protein multiple sequence alignments using Clustal Omega. Mol. Syst. Biol.7, 539 (2011).

59. Edgar, R.C., Haas, B.J., Clemente, J.C., Quince, C. \& Knight, R. UCHIME improves sensitivity and speed of chimera detection. Bioinformatics27, 2194-2200 (2011).

60. Edgar, R.C. Search and clustering orders of magnitude faster than BLAST. Bioinformatics26, 24602461(2010).

61. Caporaso, J.G. et al. Qiime allows analysis of high-throughput community sequence data. Nat. Methods7, 335-336 (2010). 
62. Caporaso, J.G. et al. PyNAST: a flexible tool for aligning sequences to a template alignment. Bioinformatics26, 266-267(2009).

63. DeSantis, T.Z. et al. Greengenes, a chimera-checked 16S rRNA gene database and workbench compatible with ARB. Appl. Environ. Microbiol.72, 5069-5072 (2006).

64. Wang, Q., Garrity, G.M., Tiedje, J.M. \& Cole, J.R. Naive Bayesian classifier for rapid assignment of rRNA sequences into the new bacterial taxonomy. Appl. Environ. Microbiol.73, 5261-5267 (2007).

65. Quast, C. et al. The SILVA ribosomal RNA gene database project: improved data processing and webbased tools. Nucleic Acid Res.41, D590-D596 (2012).

\section{Tables}

Table 1: Percentage of sequence reads contributed by bacteria present in probiotic products determined by next generation sequencing 
Product ID Bacterial species claimed by the manufacturer

\begin{tabular}{|c|c|c|}
\hline \multirow[t]{2}{*}{ Product 1} & Bacillus subtilis & $60.47 \%$ \\
\hline & Pediococcus acidilactici & $0.30 \%$ \\
\hline \multirow[t]{5}{*}{ Product 2} & Bacillus subtilis & $1.67 \%$ \\
\hline & Bacillus licheniformis & $N P *$ \\
\hline & Bacillus coagulans & $N P *$ \\
\hline & Nitrobactersp. & $N P *$ \\
\hline & Nitrosomonas sp. & $N P *$ \\
\hline \multirow[t]{4}{*}{ Product 3} & Bacillus licheniformis & $39.79 \%$ \\
\hline & Bacillus coagulans & $24.52 \%$ \\
\hline & Bacillus subtilis & $N P *$ \\
\hline & Lactobacillus acidophilus & $N P *$ \\
\hline Product 4 & Bacillus subtilis & $0.28 \%$ \\
\hline \multirow[t]{9}{*}{ Product 5} & Bacillus subtilis & $75.50 \%$ \\
\hline & Bacillus pumilus & $2.48 \%$ \\
\hline & Bacillus licheniformis & $0.99 \%$ \\
\hline & Bacillus megaterium & $N P *$ \\
\hline & Bacillus amyloliquefaciens & $N P *$ \\
\hline & Paenibacillus polymyxa & $\mathrm{NP*}$ \\
\hline & Alcaligenes faecalis & $\mathrm{NP*}$ \\
\hline & Nitrobactersp. & $\mathrm{NP*}$ \\
\hline & Nitrosomonas sp. & $N P *$ \\
\hline
\end{tabular}

*NP: Not present

\section{Figures}




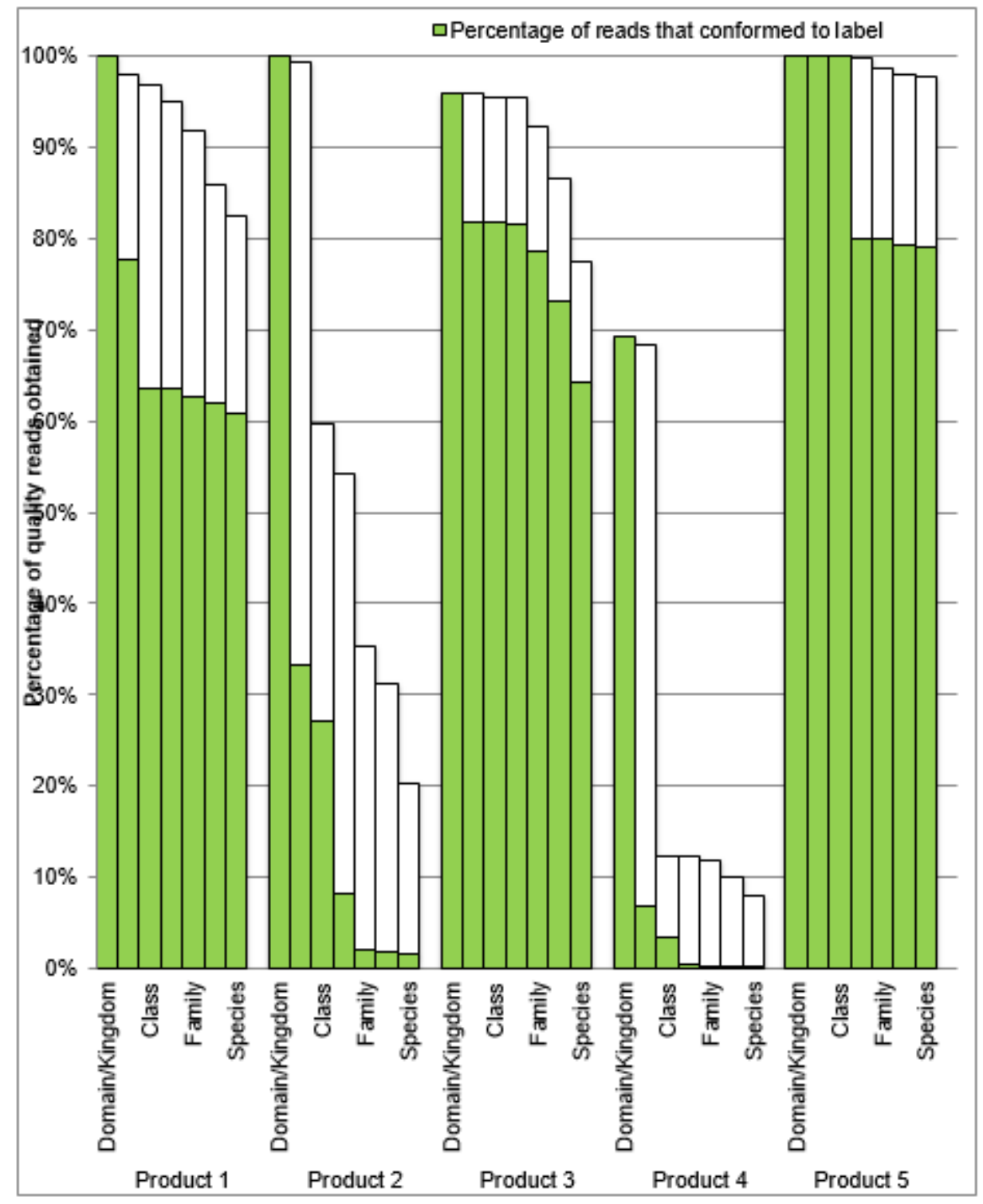

Figure 1

Taxonomic distribution of bacteria in aquaculture probiotics that conform to label information:

Percentage of quality reads categorized to the respective hierarchy level, except the unknown sequences are represented. The shaded region denotes the percentage of quality reads that match to product label claims at the respective taxonomic rank 


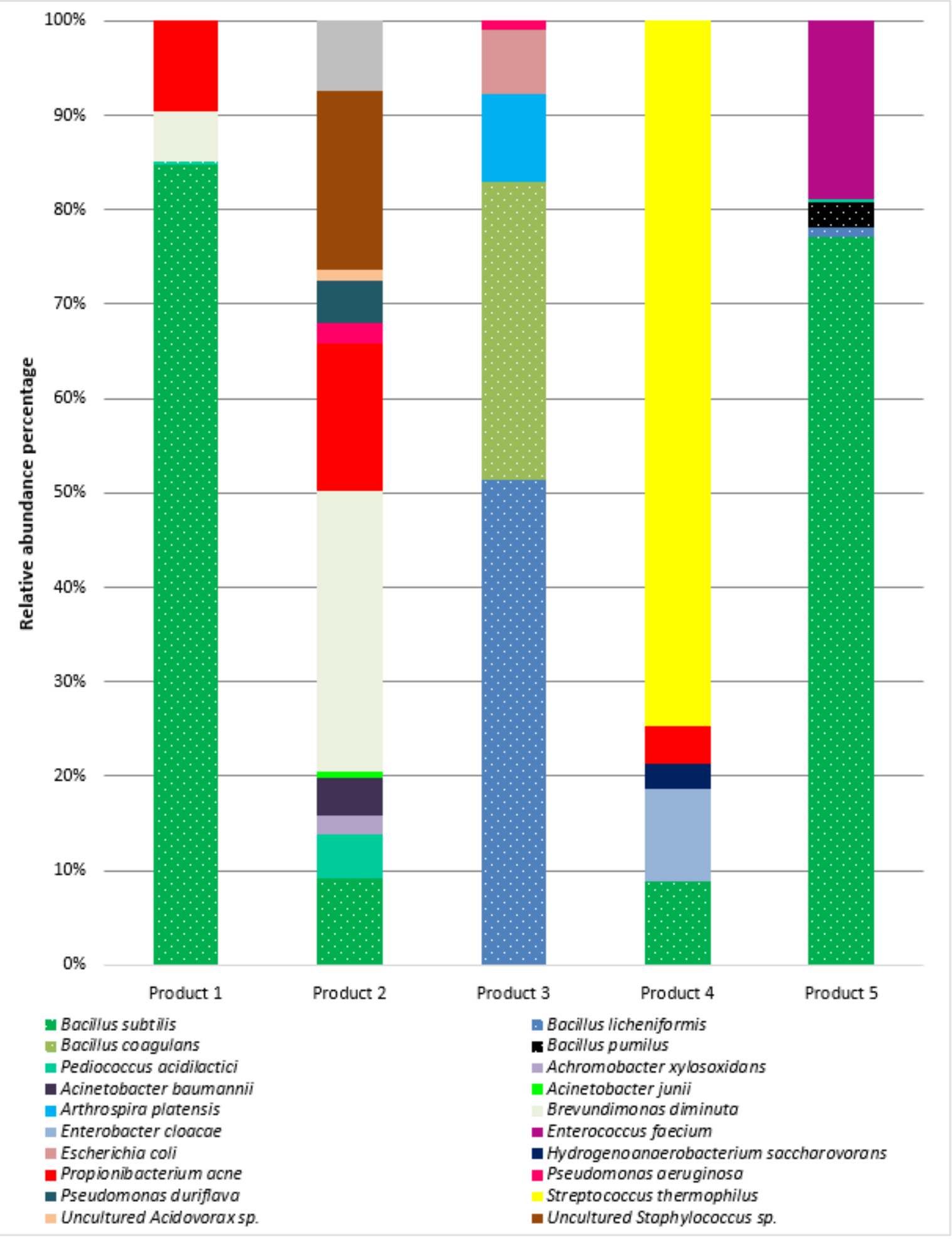

Figure 2

The relative abundance of bacterial species in probiotic products; Species with processed reads $\geq 0.1 \%$ of total quality reads were considered. Dot pattern fill represents bacteria declared on label and confirmed by sequencing 
This is a list of supplementary files associated with this preprint. Click to download.

- SupplementaryTable.pdf 